\title{
CULTURA POLÍTICA, JÓVENES Y COMUNICACIÓN: \\ UNA LECTURA DESDE LOS ESTUDIOS CULTURALES ${ }^{1}$
}

\author{
POLITICAL CULTURE, YOUTH AND COMMUNICATION: \\ AN APPROACH FROM CULTURAL STUDIES
}

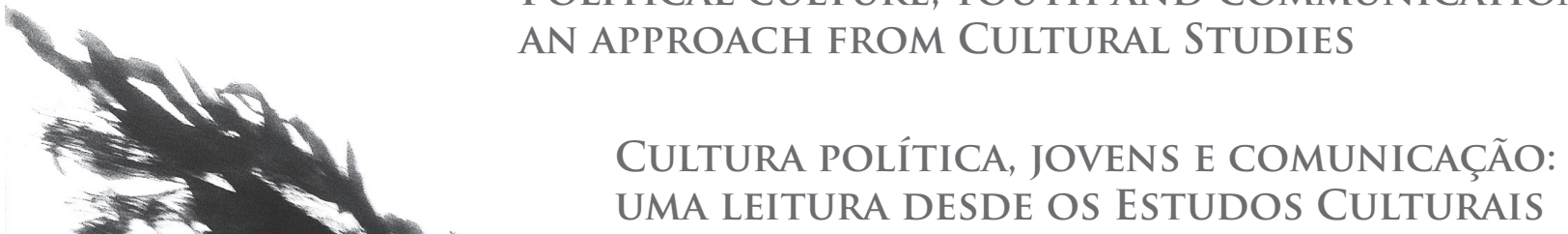

Resumen: El presente artículo plantea la teorización de tres autores en torno al concepto de cultura política (Almond y Verba, Inglehart y Merelman), para señalar que los cambios en las expresiones políticas de los jóvenes en las últimas décadas obligan a un ajuste en la formulación de la cultura política desde su relación con la comunicación en Latinoamérica. Específicamente, se expone una lectura alternativa de las expresiones políticas de los jóvenes para establecer sus culturas políticas con base en la recepción de medios, en espacios cotidianos que manifiestan la coexistencia de lo tradicional y lo alternativo, lo reaccionario y lo contestatario.

Palabras clave: Cultura política mundana, Cotidianidad, Expresiones juveniles, Audiencias 
Abstract: The current article states the theorization of three authors surrounding the concept of political culture (Almond and Verba, Inglehart and Merelman), in order to point out that the changes in the political expressions of the youth in the latest decades force a change in the formulation of the political culture from its relationship with communication in Latin America. Specifically, it shows an alternative approach to the analysis of the political expression of young people to establish their political culture on the basis of media reception, in daily spaces that manifest the coexistence of what is traditional and the alternative, which is the reactionary and argumentative.

Keywords: Worldly Political Culture, Daily Life, Juvenile Expressions, Audiences.

Resumo: Este artigo propõe a teorização de três autores em torno ao conceito de cultura política (Almond e Verba, Inglehart e Merelman), para sinalar que as mudanças nas expressões políticas dos jovens nas últimas décadas obrigam a um ajuste na formulação da cultura política desde a sua relação com a comunicação em América Latina. Especificamente, expõe-se uma leitura alternativa das expressões políticas dos jovens, para estabelecer as suas culturas políticas com base na receção de meios em espaços cotidianos que manifestam a coexistência do tradicional e o alternativo, o reacionário e o contestatário.

Palavras-chave: Cultura Política Mundana, Cotidianidade, Expressões Juvenis, Audiências.

\section{Introducción}

Desde los orígenes de la civilización occidental ha existido la preocupación por comprender de qué forma la población organiza, procesa y transforma sus imágenes sobre el entorno político en el que se desenvuelven sus instituciones (Peschard, 2001) y cómo ello se verifica en las realidades sociales de cada colectividad. Ello corresponde con un concepto que ha sido clave para las Ciencias Sociales en las últimas décadas: la cultura política.

En general, la cultura política implica dos conceptos que son complejos por sí mismos: poder y cultura. Por un lado, el poder es la base de la política, de la cual resultan cuestiones relativas al Estado, los partidos políticos, los liderazgos, las organizaciones sociales y la ciudadanía en general. En cuanto a la cultura, ella se relaciona con las creencias, comportamientos, expectativas, discursos, ceremonias, rituales, simbologías, e incluso las actuaciones sociales. Así, los análisis de la cultura política se sustentan en el deseo por establecer vínculos de causalidad entre la esfera micro y macro de la sociedad y la política. En otros términos, en el concepto de cultura política aparece implícita la tensión entre lo institucional y lo noinstitucional, entre la política y lo político. 
Pensando lo anterior, Arditi (1987, pp. 181-182) expone que la sociedad es la instancia en la que "se han cristalizado institucionalmente las relaciones de poder" a partir de la construcción de un "buen orden"; y lo social es "el vasto territorio de fenómenos, identidades y formas de vida poco institucionalizados y nomádicos" que se opone a ese "buen orden”, de allí que afirme Arditi que la sociedad no es más que una "domesticación espacial temporal y determinada de una materia maleable" como es lo social. Con esto, lo social puede ser no sólo espacio para la legitimación de la política predominante, sino para las resistencias desde lo político. En otros términos, "lo social bien podría ser un territorio de gestación de sociedad, de creación de segmentos de sociedad", como también lo social podría ser "un territorio de gestación de estrategias de resistencia conducentes a formas alternativas de hacer sociedad" (Arditi, 1987 p. 183). Así, se hace evidente que:

La forma de hacer sociedad que se desprende de la tesis acerca de la distinción sociedad/lo social se aleja de la tradición heredada del modelo de soberanía estatal de Bodin o Hobbes, de la concepción hegeliana de la totalidad social cerrada y centrada, y de las estrategias de lucha seguidas por la burguesía revolucionaria francesa. (Arditi, 1987, p. 185)

Con ello, el Estado ya no es el elemento aglutinador de otras épocas y cada comunidad política no posee homogeneidad sino heterogeneidad de expresiones políticas, de culturas políticas. Para llegar a este corolario, el concepto de cultura política ha debido pasar por distintas fases de teorización ${ }^{3}$, de las cuales sólo se mencionarán algunos autores fundamentales para este escrito.

\section{Cultura cívica para las democracias liberales}

A mediados del siglo XX se empezó a utilizar la expresión 'cultura política' para referirse a los estudios acerca de un conjunto multidimensional de fenómenos que tenían relación con las manifestaciones humanas que se expresan dentro la vida política en comunidad. Particularmente, la década de los sesenta del siglo pasado fue escenario de las primeras teorizaciones del concepto. Desde aquel entonces, el estudio realizado por Gabriel Almond y Sidney Verba se convirtió en referente obligado cuando de hablar de este tema se trata. Estos teóricos norteamericanos señalaron que era vital la actitud de los ciudadanos para generar una cultura no sólo política sino, específicamente, una cultura supeditada a los ideales democráticos occidentales del momento. Para ellos, la cultura política era

... el conjunto de actividades, creencias y sentimientos que ordenan y dan significado a un proceso político y que proporcionan los supuestos y normas fundamentales que gobiernan el comportamiento en el sistema político; abarca a la vez, los ideales políticos y las normas de actuación de una comunidad política; la manifestación en forma conjunta, de las dimensiones sicológicas y subjetivas de la política” (Almond y Verba, citado por Krotz, 1985, p.123). 
Era una época en la que, por un lado, el colectivo de referencia era la comunidad política en sentido amplio, de donde se desprendía la idea de la homogeneidad de cada sociedad (Vallés, 2008); y por otro lado, se vivían los primeros años de la Guerra Fría que promovió - durante más de cuatro décadas - la bipolaridad capitalismo vs comunismo, y que llevó al debate sobre "dos modelos de Estado moderno de participación”, el democrático y el totalitario (Almond y Verba, 1963, citado por Mejía Quintana, 2005, p. 13).

En ese contexto Almond y Verba analizaron diversos países (sobre todo del denominado Primer Mundo) y determinaron tres orientaciones básicas de la cultura política: cognitiva, afectiva y evaluativa, que equivalen, respectivamente, a cómo conocen, sienten y juzgan los individuos el sistema político en el que se insertan. El objetivo de estos investigadores era establecer cómo estas cuestiones de carácter nacional tenían una "relación significativa con el funcionamiento, estabilidad y eficacia del sistema político" (Almond y Verba, citado por Street, 2000, p.157). Quizá esta perspectiva haya coincidido con lo que en su momento hicieron pensadores como Aristóteles, Montesquieu, Rousseau, Tocqueville, Saint-Simon, o Stuart Mill, por explicar el origen y evolución de diferentes regímenes políticos (Torcal, 2000).

Para el caso de Almond y Verba, ellos establecieron que la cultura parroquial, la cultura de súbdito y la cultura participante eran las tres formas como se materializa la cultura política, y concluyeron que hay que promover una cultura cívica que respalde al correspondiente sistema político, con el fin de demostrar que cuando existe coherencia entre las actitudes de la ciudadanía y el sistema político, se da estabilidad a este último; y cuando no, el segundo abre la puerta a su inestabilidad o desaparición. Por ello, si se quería un "triunfo del modelo democrático del Estado de participación” era necesario una cultura política cívica "coordinada con la forma democrática del sistema político de participación” (Mejía Quintana, 2005, p. 13). Como se advierte, esta cultura cívica estaba pensada para respaldar decididamente a los sistemas democráticos liberales, quienes se ven favorecidos por ciudadanos "que participan (pero no demasiado) y obedecen (pero no de forma pasiva)" (Torcal, 2000, p. 234). Hace pocos años el mismo Gabriel Almond (1995) admitía el trasfondo de sus planteamientos en la década de los sesenta:

Lo que la teoría de la cultura cívica afirma es que, para que un sistema democrático funcione bien, tiene que evitar el sobrecalentamiento por un lado, y la apatía o la indiferencia por el otro, ya que debe combinar la obediencia y el respeto a la autoridad con la iniciativa y la participación, sin que haya mucho de lo uno o de lo otro, ya que no todos los grupos, intereses y temas irrumpirán simultáneamente, sino que los diferentes grupos, temas y sectores serán movilizados en distintos momentos. (Citado por Mejía Quintana, 2005, p. 11) 


\section{Postmaterialismo y juventud}

Más allá de las críticas que posteriormente recibieron los postulados de Almond y Verba durante la década de los setenta, aparecería después de la década de los ochenta una tercera etapa de los estudios acerca de la cultura política, en la que se destaca el también norteamericano Ronald Inglehart. Para Inglehart, la cultura cívica es como "un síndrome coherente de satisfacción personal, de satisfacción política, de confianza interpersonal y de apoyo al orden social establecido" (citado por Mejía Quintana, 2005, pp.10-11). En estas satisfacciones es clave el postmaterialismo - todo lo relacionado con las expresiones de autorrealización, afectividad, y participación - como motivador de las nuevas formas de expresión política, sobre todo de la juventud. Sus estudios analizaron datos recogidos por varias encuestas en diferentes países europeos, para comprobar que las distintas distribuciones de las orientaciones básicas (satisfacción con la vida, confianza interpersonal, satisfacción con la política, altos niveles de discusión política y el apoyo al orden existente) coadyuvan al funcionamiento de las instituciones democráticas (Torcal, 2000). Inglehart entendía la cultura política como "un sistema de actitudes, valores y conocimientos que son ampliamente compartidos dentro de una sociedad y que son transmitidos de generación en generación" (citado por Merelman, 1998, p.516).

Con esto, Inglehart pretendió delimitar valores, actitudes y conocimiento con el fin de establecer que las gentes están enlazadas a objetos políticos (p.e. líderes, ideales o instituciones) que son externos o están por encima de la cultura misma. Para él, la cultura política predominante en las sociedades industrializadas debía estar al servicio no sólo de la viabilidad democrática de las instituciones sino del desarrollo económico de estas sociedades (Mejía Quintana, 2005). De allí que en su definición de cultura política quede establecido que algunos valores predominan sobre otros, por ejemplo la libertad sobre la igualdad, o las gratificaciones postmateriales sobre las materiales (Merelman, 1998). Específicamente, Inglehart cree que la socialización de la postguerra se basa en la experiencia de tener cubiertas las necesidades materiales básicas, lo que generó la aparición de nuevas y superiores necesidades, y el deseo de más amplias relaciones sociales.

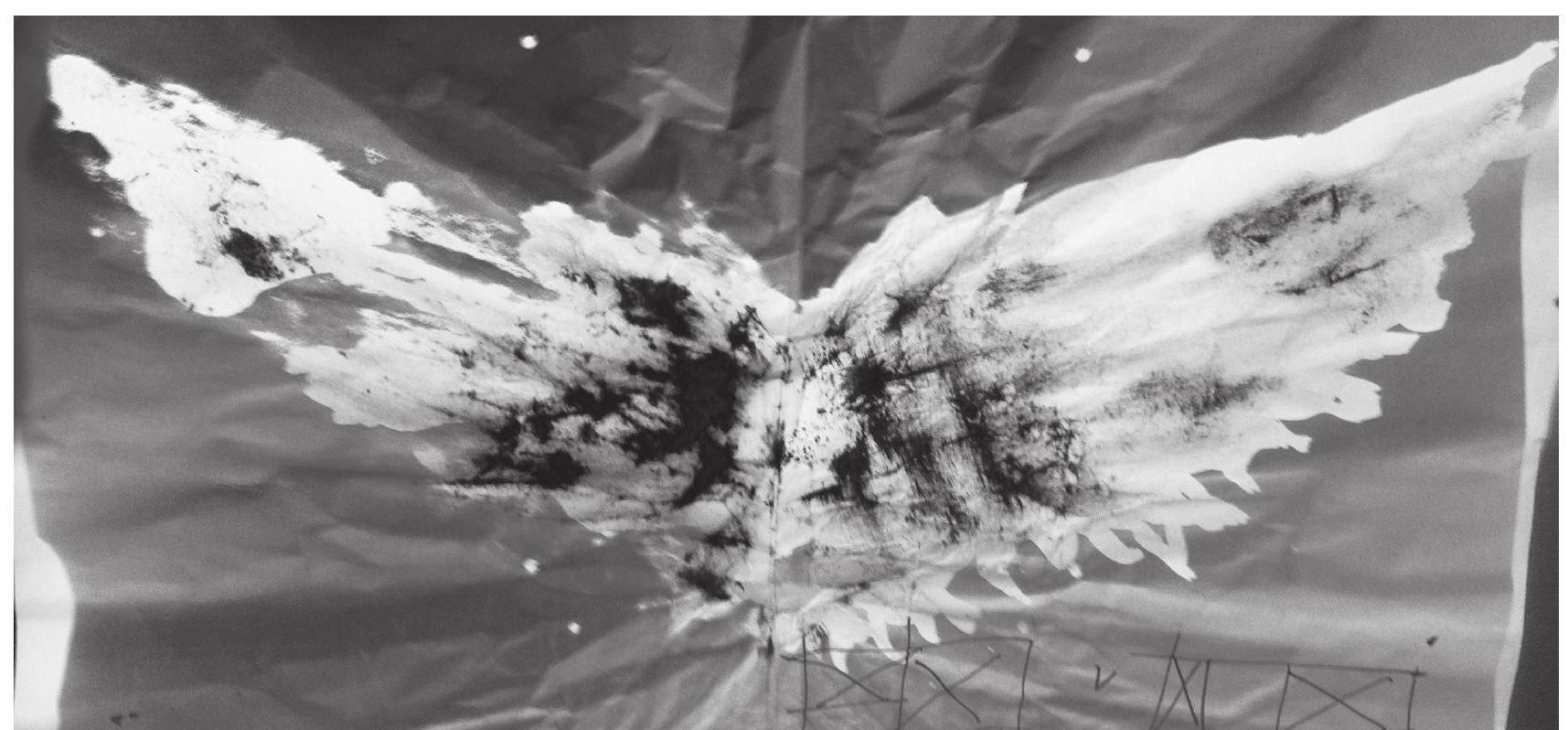


Inglehart ha defendido que la prosperidad y la paz de las que han disfrutado las sociedades industriales, han generado entre las generaciones más jóvenes un cambio cultural que propicia el progresivo aumento de los valores postmaterialistas en detrimento de los materialistas, favoreciendo, como consecuencia, la búsqueda de esos mecanismos de participación política alternativos. (Torcal, 2000, p. 243)

Aunque se abona a Inglehart su deseo de comprender las lógicas políticas de las nuevas generaciones, el análisis inglehartiano se enfocaba más bien en la relación entre la cultura y la estabilidad política, y no de la cultura con el funcionamiento propiamente de la democracia (Jack y Miller, 1996, citado por Mejía Quintana, 2005, p.11), para sugerir que a diferencia de las generaciones anteriores, las clases medias y los más jóvenes "serían los expuestos a la educación y al bienestar o al ascenso social" (Llera, 1997, p.56). Así mismo, hay que decir que esta perspectiva postmaterialista no se ajusta fácilmente a la realidad de la juventud en Latinoamérica. ¿Cómo comprender, entonces, las expresiones contemporáneas de cultura política en los jóvenes latinoamericanos?

En principio, las expresiones de la juventud pueden ser entendidas como subculturas que aparecen y se desenvuelven en su relación con la cultura predominante, marcadamente adulta. Almond y Verba afirman que las orientaciones y actitudes políticas de las personas "se desarrollan y solidifican durante la adolescencia y juventud conforme a las experiencias preadultas del individuo en el entorno familiar y las personales con el sistema (político), para mantenerse estables el resto de su vida" (Torcal, 2000, p. 235).

Sin embargo, lo anterior se ve complementado por los momentos de desacralización de la política y lo político en boca de los jóvenes latinoamericanos de hoy. "Ni los padres constituyen el patrón - eje de las conductas, ni la escuela es el único lugar legitimado del saber, ni el libro es el centro que articula la cultura" (Martín-Barbero, 1998, p.29). Específicamente, los medios divulgan informaciones que dispersan las versiones institucionales de los hechos políticos y que entre los jóvenes se mundanizan a partir de la simplificación de las temáticas en escenarios conversacionales que ellos practican a diario. Con esto, las identidades transmitidas de la generación más adulta a la más joven se debilitan, en favor de una trasmisión entre contemporáneos. Así, en términos de Margaret Mead (1971), el lugar incuestionable de la socialización en la cultura postfigurativa le da paso a una socialidad de corte cofigurativo, lo que refuerza su condición de subcultura. Afirma Morley:

Los miembros de cierta subcultura tenderán a compartir una orientación cultural a decodificar mensajes de un modo particular. Sus lecturas individuales estarán enmarcadas por formaciones y prácticas culturales compartidas que a su vez estarán determinadas por la posición objetiva que ocupa el individuo en la estructura social. (1996, p.129) 
Se debe tener en cuenta tanto el factor individual como el contexto social, y los recursos culturales de los cuales dispone el individuo en dicho contexto. En otras palabras, cada individuo es un decodificador "inmerso en un particular contexto social estructurado" (Morley, 1996, p.131). Con esto, cada sector de la audiencia juvenil "entiende" cuál es su situación en la estructura social y reacciona a ella desde su respectivo sistema de sentido.

En la construcción de cualquier cultura política son fundamentales los agentes socializadores, tales como la familia, la Iglesia, la escuela, y en el último siglo han adquirido gran relevancia los medios masivos de comunicación, al punto que hoy puede considerárseles un actor social clave en el escenario político de las democracias. Su significación se verifica en su capacidad de representar lo social, de allí que se vean comprometidos con la aparición de nuevos temas, actores e interpretaciones sociales y culturales. "Los medios han aumentado su rol de intermediarios entre instituciones del Estado y la gente, procesan la inconformidad de la ciudadanía, sensibilizan socialmente frente a intervenciones estatales en ciertas situaciones y llegan incluso a ser factores determinantes de la gobernabilidad local o nacional" (Martín-Barbero y Rey, 1999, p. 57).

Aunque la juventud en ninguna parte del mundo representa un bloque homogéneo y su ubicación espacial como grupo social rebasa los límites del barrio o la localidad, existen algunos elementos comunes a ella: la juventud es la edad de las iniciaciones (social, sexual, política, etc.). Es, también, la edad de las crisis (religiosa, de autoridad, ideológica, entre otras). Además, la juventud es la etapa en la que se aprende a darle un sentido a la vida. Esto les da un carácter especial a los jóvenes, que toman distancia con respecto a otros grupos sociales -como los adultos-, cuando particularmente exteriorizan su condición en la simple conversación cotidiana.

Con base en ello, se comprende los procesos que ocurren al interior de sectores juveniles. Más que legitimación de lo tradicional, cada joven (y sus grupos sociales específicos) puede motivarse a pensar su realidad de múltiples maneras, en pro y en contra del mundo establecido. En este orden de ideas, el partidismo, el estatismo, el clientelismo y otras expresiones de cultura política tradicional suelen entrar en crisis pues sus más recientes 'adeptos', no lo son tanto; la militancia es efímera y emocional, y los gustos ideológicos están atados a momentos precisos de la realidad política, económica y social. Ese es el reto de fortalecer los estudios de la cultura política desde la perspectiva interpretativa e interdisciplinaria de las realidades políticas y sociales que ofrecen los Estudios Culturales, con el fin "de pensar estrategias y ámbitos para el accionar de viejos y nuevos sujetos, distintos pero complementarios a los del accionar político-partidario" (Arditi, 1987, p.171). 


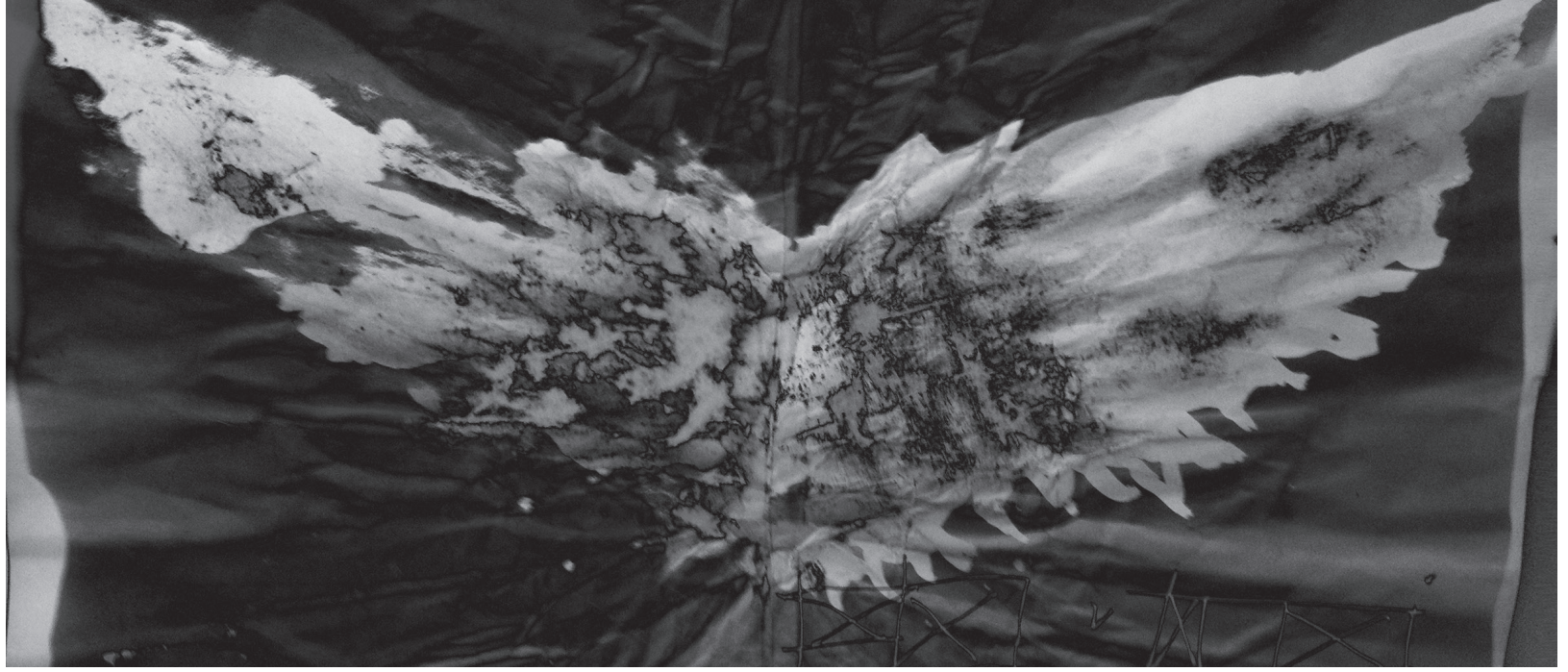

Precisamente Martín-Barbero considera que las nuevas realidades sociales de las últimas décadas están obligando a repensar las relaciones entre cultura y política "justamente en lo que ella tiene de espesor comunicativo, esto es, de trama de interpelaciones en que se constituyen los actores sociales; lo que a su vez se revierte sobre el estudio de la comunicación masiva, impidiendo que pueda ser pensada como mero asunto de mercados y consumos y exigiendo su análisis como espacio decisivo en la redefinición de lo público y en la construcción de la democracia” (1993, p.61). Ello evidenciaría la inaplicabilidad de la propuesta de Inglehart debido a que se queda corta ante la aparición de múltiples culturas políticas (en plural) que se desmarcan del modelo tradicional institucionalizado de la cultura política (en singular), particularmente en su relación con la televisión.

\section{Cultura política mundana desde la recepción televisiva}

Tanto los productores de televisión como sus receptores son objetos de estudio de por sí muy complejos, pues representan espacios de tensiones entre la cultura y el mercado, lo político y lo económico, lo social y lo individual (Capparelli y dos Santos, 2002). Esto pone en consideración la inminencia de otras lecturas de las audiencias y su relación con la política, ante los vacíos dejados por los postulados del modelo inglehartiano. La respuesta a esa invocación ha sido lo que Richard Merelman (1998) denomina cultura política mundana, un modelo que apunta a pensar cómo las personas comúnmente construyen, usan e interpretan ideas, términos y símbolos de carácter político; es decir, determinar las expresiones y consideraciones políticas que aparecen en el mundo cotidiano, muchas veces de manera asistemática e implícita.

La propuesta de Merelman no corresponde con la perspectiva teórica de la cultura política aséptica, limpia, institucionalizada, iniciada en la década de los sesenta del siglo pasado. Por el contrario, quiere poner el acento en la cultura de las gentes, tal cual como ella se da en la vida diaria, con regularidades e irregularidades. Por tanto, la cultura política mundana entiende que los actores individuales varían su discurso político, de contexto a contexto. Asimismo, las personas libremente evalúan ideas y símbolos en formas que son algunas veces lógicamente inconsistentes. Incluso hay momentos donde las personas "aplican las mismas palabras a diferentes cosas o modifican el significado de los términos según los intereses del momento” (Merelman, 1998, p. 517). 
A diferencia de Inglehart (que afirma que las situaciones políticas están atadas a momentos institucionalizados), Merelman valora los escenarios no institucionalizados de la cultura política: "Una persona puede usar un concepto político, como por ejemplo 'libertad', de manera puramente objetiva sin la observancia de un significado preciso. Por fuera de las instituciones políticas, la cultura política asume tantas formas como el discurso lo permita”. (1998, p.519). En este sentido, la cultura política es espontánea, aparece 'en vivo y en directo', en conversaciones que no tienen mediadores (como el periodista, el líder político, o el relacionista público), y en ocasiones en situaciones que no tienen como fin último el debate de tópicos políticos. Para Merelman, esto convierte a todas las formas de discursos sobre lo político en una acción política, así no estén acompañadas por un comportamiento político. Cuando Merelman se pregunta acerca de cómo la cultura política mundana ayuda a explicar la estabilidad política, él mismo responde:

La respuesta reside en el carácter multivalente y a menudo contradictorio de las ideas y símbolos de la cultura política mundana: en su desconexión de la acción política vigorosa y en el vacío de las instituciones sociales y políticas. La cultura política mundana no lleva a los ciudadanos a apoyar con entusiasmo las instituciones políticas existentes. Al contrario, sus ideas y símbolos multivalentes inhiben a los ciudadanos de cualquier participación política institucional relevante. El resultado puede ser la estabilidad política basada no en el consentimiento de principio sino más bien en la ambivalencia desactivadora. (Citado por Mejía Quintana, 2005, p.11)

Con esto, se entiende que haya culturas políticas que se mantienen al margen de cualquier actividad política, o simplemente son imperceptibles, como una especie de desobediencia civil no exteriorizada. La perspectiva de Merelman pone sobre la mesa la disputa entre lo institucional y lo no-institucional al abrir la puerta a un análisis más interpretativo de las formas que puede adoptar la cultura política ordinariamente, una perspectiva que permite "percibir y pensar una serie de fenómenos que se desarrollan en los niveles capilares, en los intersticios menos perceptibles del tejido societal, y que permita rescatar la especificidad de tales fenómenos" (Arditi, 1987, p.170).

Así entonces, las audiencias mediáticas y sus prácticas rutinarias son espacios donde puede verificarse la cultura política mundana señalada por Merelman. Particularmente, la recepción de noticias de televisión son momentos cotidianos donde aparece ese tipo de cultura política: solos o acompañados, los televidentes interpretan lo que el canal divulga, y no lo interpretan necesariamente en el sentido que quizá el periodista o el telediario pretenden establecer. Dichas interpretaciones motivan discursos de distinto tipo. 
El modo en que las audiencias responden a los mensajes que ofrecen los medios depende precisamente del grado de coincidencia -u oposición- con otros mensajes o puntos de vista que hayan encontrado en otras esferas de sus vidas. Para David Morley (1996), en el proceso de decodificación de los mensajes de los medios siempre se entrecruzan los mensajes de diversas fuentes, se tenga o no consciencia explícita de ello.

Los mensajes que recibimos de los medios no nos encuentran aislados, porque todos llevamos con nosotros, en el momento de recibirlos, otros discursos y otro conjunto de representaciones con los que estamos en contacto en otras esferas de la vida. Los mensajes del momento confluyen con otros que hemos recibido antes, mensajes explícitos o implícitos de otras instituciones, de personas conocidas o de fuentes de información en las que confiamos. (Morley, 1996, p.113)

Contrario a la fuerte creencia en la omnipotencia del emisor -propia del modelo tradicional positivista de la comunicación-, el significado del discurso masivo no es algo prefijado por quien emite, "sino el resultado de una negociación constante y variable entre la posición y el contexto de ese emisor, por un lado, y las posiciones subjetivas y contextuales de los receptores, por otro" (Méndez Rubio, 2004, p.146). En muchas ocasiones, ese receptor no está solo; está acompañado por otros, que al igual que él, pone en consideración lo que recibe de los noticieros. Particularmente, las noticias sobre política colombiana son motivadoras de discusiones que en el hogar, el restaurante o la oficina, llevan, de manera inherente o evidente, las perspectivas propias de la cultura política de los individuos que reciben dicha información.

De igual forma, el carácter etario - como el ser joven - es un elemento clave al convertirse en factor diferenciador de las interacciones; las preferencias; las acciones adecuadas e inadecuadas; y los modos de televidencia (Orozco, 2006). Así, la recepción de los medios es fundamental para entender "los procesos de re-construcción de los significados hegemónicos y para conocer con más profundidad y amplitud la generación de resistencias y contrapesos al poder" (Orozco, 2002, p.17).

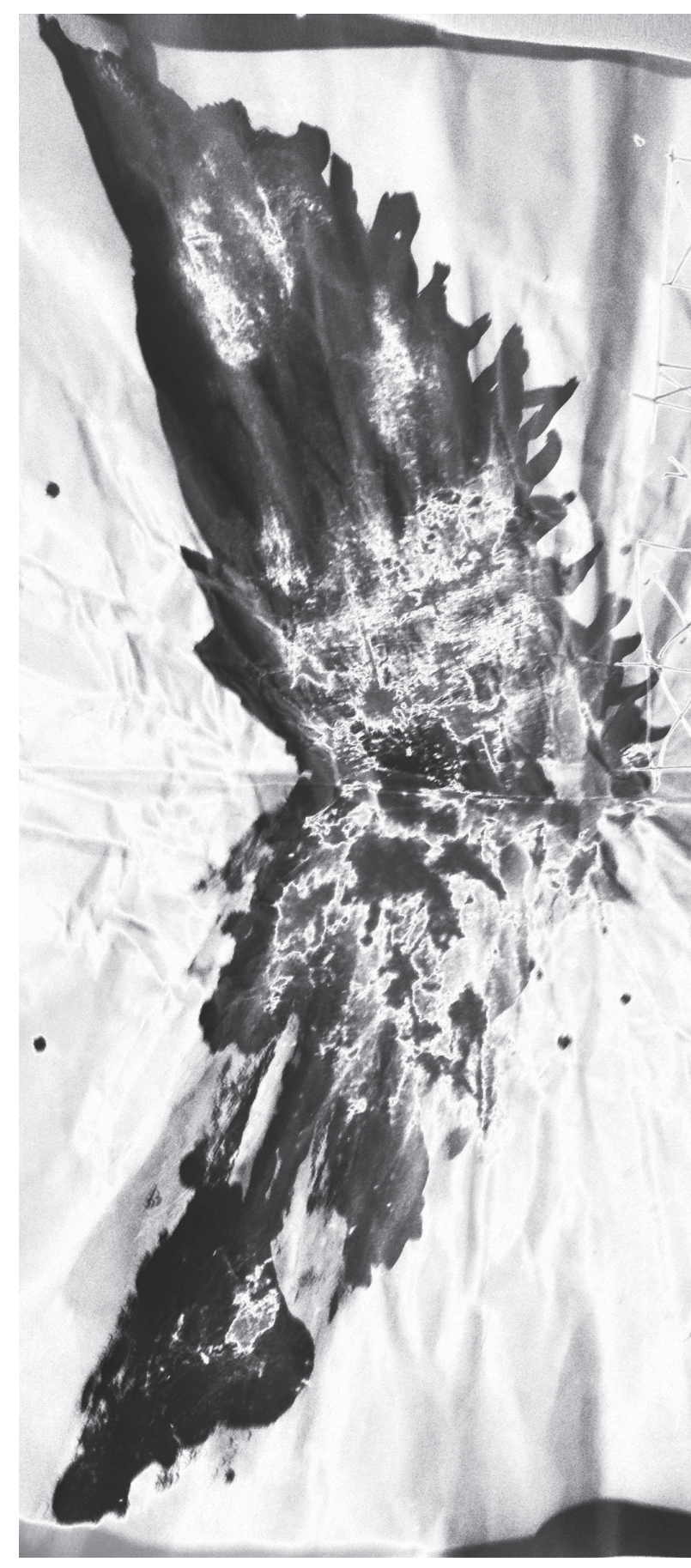


Para David Morley (1996) no sólo hay que pensar la interpretación como algo propio de la sicología de cada individuo, sino que trasciende a los grupos socioeconómicos y a las subculturas internas a cada sociedad. Con ello se pone el acento en los marcos culturales a los que tienen acceso los distintos individuos. "La diferencia que haya en nuestras respuestas a ese mensaje debe relacionarse también con nuestros distintos orígenes sociales, con el modo en que estos nos suministran diferentes instrumentos culturales, diferentes marcos conceptuales que llevamos a nuestra relación con los medios" (Morley, 1996, p. 119). Por ello, es fundamental tener en cuenta todas las formas culturales (o subculturas) que se manifiestan al interior de la cultura predominante, entendidas como "sistemas de sentido" y "modos de expresión" de sectores particulares de la estructura social que dan trámite a las contradicciones en cada situación social que comparten.

Todo lo anterior confirma el llamado que hace Jesús MartínBarbero para que se adelanten indagaciones apoyadas en los Estudios Culturales como enfoque interdisciplinar para comprender los flujos de los medios en los "mundos de vida de la gente", en grupos sociales como los jóvenes donde se combina no sólo las hibridaciones globales sino también las resistencias locales. "La cultura cotidiana de las mayorías desafía a fondo nuestros esquemas al apropiarse de la modernidad sin dejar su cultura oral, al estar gramaticalizada no por la sintaxis del libro, sino por los dispositivos narrativos de la radio, el cine y la televisión. La nueva sensibilidad convierte el estudio de la comunicación en tarea de envergadura antropológica" (MartínBarbero, 1993, p.64).

\section{A manera de conclusión}

Hoy las múltiples manifestaciones juveniles son la expresión del disputado valor al reconocimiento y a la autonomía de hacer política por fuera de los estándares tradicionales. Las culturas políticas de los jóvenes se basan en sus múltiples identidades, y en las formas de consumo de información televisada que expresan tanto la defensa de la institucionalidad, como la participación en fenómenos alternativos globales que los mass media divulgan.

En un mundo con identidades fragmentadas, producto de los múltiples universos simbólicos de los que participan, las causas políticas juveniles suelen ser dispersas y cortoplacistas. Por eso, los agentes del partidismo, el estatismo, el clientelismo y otras expresiones de la política tradicional latinoamericana se intranquilizan ante la presencia de una generación que ve la militancia política como algo baladí y los gustos ideológicos como momentos precisos atados a acontecimientos políticos de la realidad de cada país. 
Lamentablemente han predominado análisis que sobrevaloran el orden político y el estado de cosas tradicional, soslayando los claroscuros en las expresiones políticas que a diario se dan en la recepción de las audiencias. En tal sentido, la realidad de América Latina posee un carácter tan sui generis, que obliga a que las propuestas de análisis de la cultura política se desmarquen del empirismo de la corriente positivista - propia de la línea de Almond y Verba - para darle mayor vuelo a una lectura problematizadora de estas realidades - planteada por Merelman. Esto coincide con lo afirmado por Lechner (1987, p.254) quien propone aplicar sobre las realidades de Latinoamérica "un enfoque dialéctico que aborde en conjunto las formas de democratización y los problemas históricos" como manera de reconocer el valor positivo de la pluralidad y la heterogeneidad existente en el continente.

A partir de allí, la participación directa de las gentes desde su cotidianidad haría de la política un constructo social que por momentos puede incluso contravenir los ideales institucionalizados del momento, o mezclar elementos en apariencia contradictorios. Si consideramos los rasgos tradicionales de la cultura política en Colombia - el bipartidismo, la violencia, el clientelismo, la concepción de pueblo, la religión católica, la izquierda, la tradición civilista, y el individualismo- (Guevara Cobo, 1999), combinadas con las expresiones propias de la sociedad colombiana contemporánea -más heterogénea, plural, laicizada y fragmentada- (Martín-Barbero y Rey, 1999), podríamos establecer que nuestra democracia en la vida diaria se desenvuelve de manera conflictiva y paradojal, lo que dejaría sin piso las lecturas que siguen la línea teórica de Almond y Verba para darle paso a análisis de corte merelmaniano.

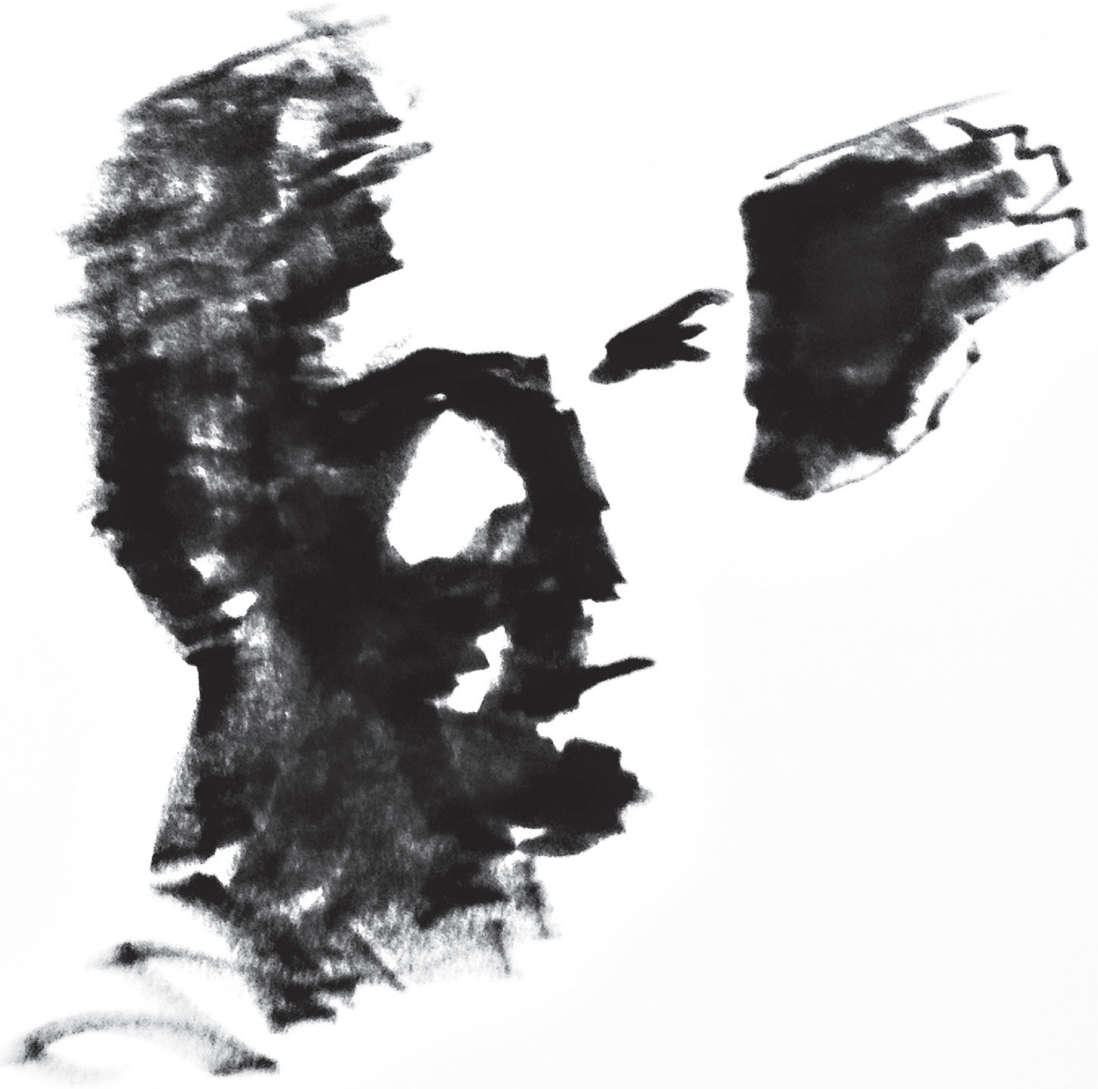




\section{Notas}

${ }^{1}$ La presente es una síntesis del marco teórico de la investigación "Las culturas políticas de universitarios del pregrado de Comunicación de la Universidad Cooperativa, sede Medellín, a partir del consumo de noticias televisadas relacionadas con política colombiana”, realizada entre los años 2013 y 2014.

2 Comunicador social - periodista. Magister en Historia. Investigador principal de la investigación mencionada en la anterior nota al pie.

${ }^{3}$ Antonio Mursia Frassineti (2008) expone, grosso modo, tres etapas de los estudios sobre cultura política: la primera, iniciada en la década de los sesenta por la obra fundacional de Almond y Verba, y multiplicada sólo por estudiosos norteamericanos; la segunda, correspondiente a la década de los setenta en la que se critica al concepto a partir de sus debilidades y limitaciones teóricas y metodológicas; y una tercera etapa de renacimiento, en la década de los ochenta, en la que autores de distintos puntos del planeta reasumen o ajustan los postulados de Almond y Verba.

\section{Referencias}

Arditi, Benjamín (1987). Una gramática postmoderna para pensar lo social. En Lechner, Norbert, Cultura política y democratización. Chile: Clacso

Capparelli, Sergio, y Dos Santos, Susy. (2002). La televisión en Brasil. En Orozco, Guillermo (dir.) Historias de la televisión en América Latina. Barcelona: Gedisa

Guevara Cobos, Eduardo. (1999, diciembre). Aproximaciones sociológicas en torno a la cultura política colombiana. Reflexión política, Vol. 1. (2). Recuperado de: http://www.redalyc.org/ pdf/110/11010209.pdf

Krotz, Esteban. (1985, diciembre). Hacia la cuarta dimensión de la cultura política. Iztapalapa, Revista de Ciencias Sociales y Humanidades, Vol. 1 (12), pp. 121-128. Recuperado de: http: / / tesiuami.uam. $\mathrm{mx} /$ revistasuam $/$ iztapalapa $/$ include $/$ getdoc.php?id $=1104 \&$ article $=1127 \&$ mode $=p d f$

Lechner, Norbert. (1987). La democratización en el contexto de una cultura posmoderna En Cultura política y democractización

Lechner, Norbert. (1988). Estado y política en América Latina. México: Siglo Veintiuno Editores.

Llera, Francisco J. (1997). Enfoques en el estudio de la cultura política en Cultura política: Enfoques teóricos y análisis empíricos. Del Castillo, Pilar y Crespo Ismael. España:Tirant Lo Blanch

Martín-Barbero, Jesús. (1993). La comunicación en las transformaciones del campo cultural. Alteridades. Vol. 3 (5), pp. 59-68.

. (1998). Comunicación y ciudad: sensibilidades, paradigmas, escenarios. En Giraldo, Fabio, y Viviescas, Fernando (compiladores), Pensar la ciudad. Bogotá: Tercer Mundo

Martín-Barbero, Jesús, y Rey, Germán. (1999). Los ejercicios del ver: Hegemonía audiovisual y ficción televisiva. Barcelona: Gedisa 
Mead, Margaret (1971). Cultura y compromiso: Estudio sobre la ruptura generacional. Argentina: Granica

Mendez Rubio, Antonio. (2004). Perspectivas sobre comunicación y sociedad. España: Universitat Autónoma de Barcelona.

Mejía Quintana, Oscar - director - (2005, junio). Cultura política, ciudadanía y democracia: Retos y perspectivas en la construcción de una democracia disputatoria en Colombia. Cuadernos de Ciencia Política. Vol. 2 (3), pp.9-34

Merelman, Richard. (1998, septiembre). The Mundane Experience of Political Culture, Political Communication, Vol. 15 (4), pp. 515-535.

Morley, David. (1996). Televisión, audiencias y estudios culturales. Buenos Aires: Amorrortu.

Murga Frassinetti, Antonio. (2008, septiembre). Cultura política: Un inventario bibliográfico. Revista de Ciencias Sociales. No. 121, pp. 107-131.

Orozco Gómez, Guillermo. (2002). Recepción y mediaciones: Casos de investigación en América Latina. Bogotá: Norma.

. (2006). Televidencias y mediaciones: La construcción de estrategias por la audiencia. En Sunkel, Guillermo (coord.) El consumo cultural en América Latina: Construcción teórica y líneas de investigación. Bogotá: Convenio Andrés Bello.

Peschard, Jacqueline. (2001). La cultura política democrática. México: Instituto Federal Electoral.

Street, John. (2000). Politica y cultura popular. Madrid: Alianza.

Sodré, Muniz. (1998). Reinventando la cultura: La comunicación y sus productos. Barcelona: Gedisa

Torcal, Mariano. (2000). Cultura política. En Del Aguila, Rafael (ed), Manual de Ciencia Política. Madrid: Trotta

Vallés, Josep. (2008). Ciencia política: una introducción. Barcelona: Ariel.

Recibido: abril 30 / Aprobado: junio 1 de 2015 